\title{
CIRCULATION OF THE BLOOD
}

The Control of the Circulation of the Blood By Prof. R. J. S. McDowall, with the assistance of Lt.-Col. G. E. Malcomson and I. MeWhan. Pp. $\mathbf{x v}+619$. (London, New York and Toronto: Longmans, Green and Co., Ltd., 1938.) 73s. 6d. net.

PROF. McDoWALL is to be congratulated on the production of a comprehensive 'Handbook' on the control of the circulation of the blood, with seven thousand references to other works. It is surprising that he has found time to write it without interrupting either his teaching or his research work. His book covers the ground as completely as such books can, and does not follow the easy course of disposing of early work by reference to previous reviews, but contains much discussion of work published before 1900 , where such work is still considered important.

A few minor errors are inevitable, and a warning to this effect is contained in the preface. They can do little harm, since no serious man of science would rely on a monograph without referring to the original literature. The 38 figures are all taken from the author's own experiments, and their even distribution through the book reflects his close practical knowledge of all the problems discussed.

There are 150 pages dealing with the control of the blood vessels in various parts of the body, 100 pages on the heart, 80 pages on adrenaline, and chapters on the effects of carbon dioxide, anoxæmia, temperature, sleep, exercise, posture, hæmorrhage, the pituitary, the hypothalamus, and vasodilator substances. The action of ions and the chemical transmission of nervous impulses are deliberately and wisely omitted; but it is a pity that there is no adequate account of the various theories that have been propounded to account for vascular shock. Perhaps the explanation is that the book has been confined to physiological phenomena, and shock is excluded as pathological.

All physiologists who work on the circulation will covet this book, which will give them a long. list of references, and a considered summary of many problems. It will save some of them from arduous searches in libraries and others from the publication of facts already known.

J. H. Gaddum.

\section{STUDIES IN TELEPATHY}

Experiments in Telepathy

By René Warcollier. Edited and abridged by Gardner Murphy from "La Télépathie", articles in the Revue Métapsychique, and recent Unpublished Studies. Translated by Josephine B. Gridley. Pp. viii +250 . (London: George Allen and Unwin, Ltd., 1939.) $7 s .6 d$. net.

$\mathrm{T}_{\mathrm{H}}^{\mathrm{H}} \mathrm{m}$ HIS book is a collection of material taken from various publications by $M$. René Warcollier and put together with a foreword by Prof. Gardner Murphy of the Department of Psychology of Columbia University.

For some thirty years, M. Warcollier has been studying the phenomena ascribed to telepathy, and in this volume he sums up his impressions of what he has learnt and gives numerous examples of successes in the reproduction of drawings, diagrams, etc., many of which are clearly not due to chance alone.

The main object of this collection of papers is not so much to offer fresh evidence for the existence of a telepathic faculty as to study and discuss the mental processes involved, and to try to ascertain how to produce the phenomena at will and thereby to initiate a detailed examination of the laws underlying them. Although the author was not successful in discovering any basic laws, his notes provide suggestive material for future experimenters. Thus some of his results indicate that ideas repressed by the agent seem to be transmitted better than those upon which his attention has been concentrated; whilst the factor of the agent's own activity as compared with that of the percipient is seen in a number of experiments. On the other hand an increase in the number of agents seems to lessen their influence, whereas the opposite is true as regards the percipients, who, in certain cases, appear to be in mental rapport with one another.

Although much of M. Warcollier's work does not seem to be open to the kind of statistical treatment which is now being applied to problems of this kind, and through which we may hope to gain a greater insight into the questions involved, his work is of considerable interest, since he is particularly concerned with the kind of mental factors at work if the phenomenon is a real effect and not due to unascertained normal causes. 